\title{
RESEARCH
}

Open Access

\section{Effect of statins on post-contrast acute kidney injury: a multicenter retrospective observational study}

\author{
Maoning Lin ${ }^{1,2+}$, Tian $\mathrm{Xu}^{1,2+}$, Wenjuan Zhang ${ }^{3}$, Duannbin $\mathrm{Li}^{1,2}, \mathrm{Ya} \mathrm{Li}^{1,2}, \mathrm{Xulin}_{\text {Hong }}{ }^{1,2}, \mathrm{Yi}_{\mathrm{i}}$ Luan $^{1,2^{*}}$,
} Wenbin Zhang ${ }^{1,2^{*}}$ and Min Wang ${ }^{1,2^{*}}$ (D)

\begin{abstract}
Background: Post-contrast acute kidney injury (PC-AKI) is a severe complication of coronary angiography (CAG) and percutaneous coronary intervention (PCI). Currently, the effect of statins on PC-AKI and its mechanism remains unclear.

Methods: This multicenter retrospective observational study included 4386 patients who underwent CAG or PCl from December 2006 to December 2019 in Sir Run Run Shaw Hospital and its medical consortium hospitals. Serum creatinine pre- or post-procedure within $72 \mathrm{~h}$ after $\mathrm{PCl}$ was recorded. Multivariate logical regression was used to explore whether preoperative use of statins was protective from PC-AKI. The path analysis model was then utilized to look for the mediation factors of statins.
\end{abstract}

Results: Four thousand three hundred eighty-six patients were enrolled totally. The median age of the study population was 68 years old, $17.9 \%$ with PC-AKI, and $83.3 \%$ on preoperative statins therapy. The incidence of PC-AKI was significantly lower in group of patients on statins therapy. Multivariate regression indicated that preoperative statins therapy was significantly associated with lower percentage of elevated creatinine $(\beta:-0.118, P<0.001)$ and less PC-AKI (OR: $0.575, P<0.001)$. In the preoperative statins therapy group, no statistically significant difference was detected between the atorvastatin and rosuvastatin groups (OR: 1.052, $P=0.558$ ). Pathway model analysis indicated a direct protective effect of preoperative statins therapy on PC-AKI $(P<0.001)$, but not through its lipid-lowering effect $(P=0.277)$ nor anti-inflammatory effect $(P=0.596)$. Furthermore, it was found that "low-density lipoprotein cholesterol $(\mathrm{LDL}-\mathrm{C}) \rightarrow \mathrm{C}$-reactive protein $(\mathrm{CRP})^{\prime \prime}$ mediated the relationship between preoperative statins therapy and PC-AKI $(P=$ 0.007). However, this only explained less than $1 \%$ of the preoperative protective effects of statins on PC-AKl.

Conclusion: Preoperative statins therapy is an independent protective factor of PC-AKI, regardless of its type. This protective effect is not achieved by lipid-lowering effect or anti-inflammatory effect. These findings underscore the potential use of statins in preventing PC-AKI among those at risk.

Keywords: Post-contrast acute kidney injury, Statins, Lipid-lowering effect, Anti-inflammatory effect, Percutaneous coronary intervention, Path analysis, Mediation analysis

\footnotetext{
* Correspondence: ryan1218@zju.edu.cn; 3313011@zju.edu.cn; wangminsyf30508@zju.edu.cn

${ }^{\dagger}$ Maoning Lin and Tian Xu contributed equally to this work.

'Department of Cardiovascular Diseases, Sir Run Run Shaw Hospital, College

of Medicine, Zhejiang University, No 3 East of Qinchun Road, Hangzhou,

Zhejiang 310000, People's Republic of China

Full list of author information is available at the end of the article
}

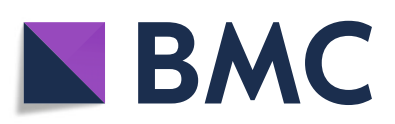

(c) The Author(s). 2021 Open Access This article is licensed under a Creative Commons Attribution 4.0 International License, which permits use, sharing, adaptation, distribution and reproduction in any medium or format, as long as you give appropriate credit to the original author(s) and the source, provide a link to the Creative Commons licence, and indicate if changes were made. The images or other third party material in this article are included in the article's Creative Commons licence, unless indicated otherwise in a credit line to the material. If material is not included in the article's Creative Commons licence and your intended use is not permitted by statutory regulation or exceeds the permitted use, you will need to obtain permission directly from the copyright holder. To view a copy of this licence, visit http://creativecommons.org/licenses/by/4.0/ The Creative Commons Public Domain Dedication waiver (http://creativecommons.org/publicdomain/zero/1.0/) applies to the data made available in this article, unless otherwise stated in a credit line to the data. 


\section{Introduction}

Post-contrast acute kidney injury (PC-AKI), defined as "an increase in serum creatinine $\geq 0.3 \mathrm{mg} / \mathrm{dl}(26.5 \mu \mathrm{mol} /$ l), or $\geq 1.5$ times the baseline value within $48-72 \mathrm{~h}$ of exposure to a contrast medium (CM)" $[1,2]$, accounts for up to $30 \%$ of acute kidney injury in hospitalized patients [3]. Millions of cardiac catheterizations are currently performed every year [4], and hence the concerns about PC-AKI have grown recently. Prevention of PC-AKI remains dependent on volume expansion with sodium bicarbonate or normal saline. However, the benefit of drugs such as statins, N-acetylcysteine, angiotensinconverting enzyme inhibitors (ACEI) and ezetimibe in PC-AKI's prevention remains unclear. According to the latest guidelines on European Society of Urogenital Radiology (ESUR) [2], there are no specific effective preventive measures of PC-AKI other than volume expansion.

Statins play an essential role in the cardiovascular field, but their effects on PC-AKI are inconsistent. There is no consensus among experts on the usefulness of pretreatment with statins. This is despite the 2014 European Society of Cardiology's guidelines which stated that shortterm and high-intensity statins therapy reduces the risk of PC-AKI in patients undergoing myocardial revascularization [5]. While some studies have reported a reduction in PC-AKI events among statins users [6-10], others did not show such benefit [11-15], and one study even demonstrated more PC-AKI outcomes with statins [13]. Given these contradicting results, current PC-AKI guidelines do not recommend statins. Nevertheless, these studies were focused on exploring the effects of short-term, high-dose statins or high plasma exposure of statins on PC-AKI.

On the other hand, up to the current knowledge, few studies addressed the association between long-term use of statins (> 8 weeks) before CM and PC-AKI. Furthermore, the most recent ESUR guidelines, mentioned that the effects of long-term statins on PC-AKI are unclear in patients undergoing CAG/PCI [2]. Therefore, one of the study's objectives was to explore the long-term statins use's impact before receiving CM on PC-AKI.

The pathophysiology of PC-AKI is not exactly understood, and several studies trying to fill gaps in knowledge are underway [16-19]. Three basic mechanisms have been proposed that act together on $\mathrm{PC}$-AKI: reactive oxygen species formation, tubular cell toxicity, and medullary hypoxia with renal vasoconstriction $[16,17,20$, 21]. Statins, known for their lipid-lowering effects, also have other non-lipid modifiable effects, named pleiotropic effects [22], of which the most important effects are reducing oxidative stress [23-26] and antiinflammatory [27]. The pleiotropic effect of statins may have important clinical significance in preventing PCAKI [7]. Few prior study explored the intermediate mechanism of statins. Thus, in addition to exploring the effectiveness of long-term use of statins on PC-AKI, this study used path analysis methods based on clinical test indicators, LDL-C and CRP, to explore the specific mechanisms by which statins may favorably impact PCAKI.

\section{Methods}

\section{Study design and setting}

This was a multicenter retrospective observational study. The study included 4386 consecutive patients who underwent CAG or PCI from December 2006 to December 2019 in Sir Run Run Shaw Hospital and its medical consortium hospitals. Patients with terminal-stage renal disease or under hemodialysis before the operation, patients younger than 18 years, and patients with missing serum creatinine pre- or post-procedure in $72 \mathrm{~h}$ after PCI were excluded. The study was approved by the Ethics Committee.

\section{Definitions}

PC-AKI was defined according to the ESUR as an increase in serum creatinine $\geq 26.5 \mu \mathrm{mol} / \mathrm{l}(0.3 \mathrm{mg} / \mathrm{dl})$ or $\geq$ 1.5 times the baseline value within $48-72 \mathrm{~h}$ of contrast medium (CM) exposure. Preoperative statins use was defined as patients with long-term statins usage more than 8 weeks before CAG or PCI. CM in excess was defined as the ratio of CM volume $(\mathrm{ml}) / \mathrm{eGFR}\left(\mathrm{ml} / \mathrm{min} / 1.73 \mathrm{~m}^{2}\right)$ exceeded three times, according to ESUR [1].

\section{Data collection}

The data collected from Hospital Information System (HIS) included age, gender, body mass index (BMI), comorbidities, and current medication. The details of the procedure, and results of laboratory blood biochemical tests were documented. Serum creatinine concentrations were assessed in all patients at hospital admission. The postoperative serum creatinine concentrations recorded were the highest level measured at least 3 times within a 72- timeframe. Patients who used long-term statins before the operation were divided into two groups: rosuvastatin and atorvastatin. The endpoint was developing PC-AKI.

\section{Data analysis}

Statistical Package for Social Sciences (SPSS version 20) was applied for all statistical analysis. $P$ values $<0.05$ was considered as statistically significant in this study. Continuous variables were presented as median/interquartile range and groups were compared with nonparametric tests. Categorical variables were presented as frequencies/percentages, and Chi-square analysis was used in groups. Linear regression analysis was utilized to explore the significant predictors of the percentage of elevated 
creatinine (continuous variable), while logistic regression analysis was utilized for exploring the significant predictors of PC-AKI (binary variable). SPSS Amos was used to analyze the direct and indirect effects of statins on PC-AKI.

\section{Results}

\section{Baseline characteristics}

Table 1 summarized baseline clinical characteristics stratified by PC-AKI status. A total of 4386 patients were enrolled. The median age was 68 years old, $66 \%$ were male, $63.6 \%$ had hypertension and $24.1 \%$ had diabetes. The baseline LDL cholesterol was $2.08 / 1.13 \mathrm{mmol} / \mathrm{L}$, the baseline CRP was $2.3 / 7.13 \mathrm{mg} / \mathrm{L}$, and $4.6 \%$ of the patients used $\mathrm{CM}$ in excess. About $83.3 \%$ of patients received preoperative statins therapy on admission.
Compared with patients in the non-PC-AKI group, patients with PC-AKI were more likely to be older (70/13 vs. $68 / 13 ; P<0.001)$, less male $(60.1 \%$ vs. $67.3 \% ; P<0.001)$ and drinkers $(12.5 \%$ vs. $16 \%$; $P=0.038)$. Patients in the PC-AKI group also had lower prevalence of preoperative therapy (76.6\% vs. $84.8 \%$; $P<0.001)$, lower eGFR $(83.02 / 38.1$ vs. $84.61 / 27.41 ; P=0.012)$, lower left ventricular ejection fractions (LVEF) (59.5/17.9 vs. 62.8/14.53; $P<0.001$ ), higher CRP $(4.4 / 14.8$ vs. $2 / 5.8, P<0.001)$, and higher proportion of excess volumes of $\mathrm{CM}(6.6 \%$ vs. $4.2 \%, P=0.005)$, and more prevalence of diabetes mellitus $(28.2 \%$ vs. $23.2 \%, P=0.003)$. There were no significant differences between the groups in smoking status, hypertension, uric acid, LDL-C, angiotensin converting enzyme inhibitors (ACEI), diuretic, ezetimibe, aspirin, type and volume of $\mathrm{CM}$, history of myocardial infarction and cardiac surgery, type of operation, multi vessel PCI and total length of stents.

Table 1 Baseline

\begin{tabular}{|c|c|c|c|c|}
\hline & Total $(n=4386)$ & non-PC-AKI ( $n=3599)$ & PC-AKI $(n=787)$ & $P$ \\
\hline Male, n/\% & 2895/66 & $2422 / 67.3$ & $473 / 60.1$ & $<0.001$ \\
\hline Age, years & $68 / 13$ & $68 / 13$ & $70 / 13$ & $<0.001$ \\
\hline Smoking, n/\% & $744 / 17$ & $628 / 17.4$ & $116 / 14.7$ & 0.067 \\
\hline Drinking, n/\% & $674 / 15.4$ & $576 / 16$ & $98 / 12.5$ & 0.012 \\
\hline Hypertension, n/\% & $2788 / 63.6$ & $2274 / 63.2$ & $514 / 65.3$ & 0.261 \\
\hline Diabetes, n/\% & $1058 / 24.1$ & $836 / 23.2$ & $222 / 28.2$ & 0.003 \\
\hline $\mathrm{eGFR}, \mathrm{mL} / \mathrm{min} / 1.73 \mathrm{~m} 2$ & $84.38 / 28.9$ & $84.61 / 27.41$ & $83.02 / 38.1$ & 0.012 \\
\hline Uric acid, $\mu \mathrm{mol} / \mathrm{L}$ & $364 / 135$ & $364 / 131$ & $364 / 150$ & 0.504 \\
\hline LDL-C, mmol/L & $2.08 / 1.13$ & $2.08 / 1.12$ & $2.08 / 1.18$ & 0.485 \\
\hline $\mathrm{CRP}, \mathrm{mg} / \mathrm{L}$ & $2.3 / 7.13$ & $2 / 5.8$ & $4.4 / 14.8$ & $<0.001$ \\
\hline LVEF, \% & $62 / 16$ & $62.8 / 14.53$ & $59.5 / 17.9$ & $<0.001$ \\
\hline Pre-operative statin therapy, n/\% & $3654 / 83.3$ & $3051 / 84.8$ & $603 / 76.6$ & $<0.001$ \\
\hline Atorvastatin, n/\% & $2307 / 63.1$ & $1906 / 62.5$ & $401 / 66.5$ & 0.173 \\
\hline ACEI, $n / \%$ & $704 / 16.1$ & $565 / 15.7$ & $139 / 17.7$ & 0.174 \\
\hline Diuretic, n/\% & $1383 / 31.5$ & $1124 / 31.2$ & 259/32.9 & 0.359 \\
\hline Aspirin, $n / \%$ & $3632 / 82.8$ & $2969 / 82.5$ & $663 / 84.2$ & 0.206 \\
\hline Ezetimibe, n/\% & $275 / 6.3$ & $237 / 6.6$ & $38 / 4.8$ & 0.066 \\
\hline Excess volumes of $\mathrm{CM}, \mathrm{n} / \%$ & $185 / 4.6$ & $137 / 4.2$ & $48 / 6.6$ & 0.005 \\
\hline Iso-osmolar CM, n/\% & $1380 / 31.6$ & $1132 / 31.6$ & $248 / 31.6$ & 0.988 \\
\hline Contrast Volume, ml & $80 / 80$ & $80 / 80$ & $80 / 90$ & 0.249 \\
\hline Prior myocardial infarction, $\mathrm{n} / \%$ & $71 / 1.6$ & $58 / 1.6$ & $13 / 1.7$ & 0.935 \\
\hline Prior $\mathrm{PCl}, \mathrm{n} / \%$ & $230 / 5.2$ & $191 / 5.3$ & May-39 & 0.689 \\
\hline Prior CABG, n/\% & $15 / 0.3$ & $14 / 0.4$ & $1 / 0.1$ & 0.254 \\
\hline Prior cardiac surgery /except CABG, n/\% & $15 / 0.3$ & $11 / 0.3$ & $4 / 0.5$ & 0.378 \\
\hline Angiography combined with $\mathrm{PCl}, \mathrm{n} / \%$ & $1925 / 43.9$ & $1571 / 43.7$ & $354 / 45$ & 0.496 \\
\hline Multi vessel $\mathrm{PCl}, \mathrm{n} / \%$ & $1075 / 56.2$ & $878 / 56.2$ & $197 / 56.1$ & 0.977 \\
\hline Total length of stents, mm & $38 / 38$ & $39 / 39$ & $36 / 33.5$ & 0.083 \\
\hline
\end{tabular}

Abbreviations: $P C$ - $A K I$ post-contrast acute kidney injury, eGFR estimated glomerular filtration rate, $L D L-C$ low-density lipoprotein cholesterol, $C R P C$-reactive protein, $\angle V E F$ left ventricular ejection fractions, $C M$ contrast medium, $A C E I$ angiotensin converting enzyme inhibitors, $P C I$ percutaneous coronary intervention, $C A B G$ coronary artery bypass grafting 


\section{Regression analysis}

Table 2 showed the associations of different risk factors with PC-AKI using logistics regression analysis. Seven variables were significantly associated with PC-AKI, including age, male, diabetes, CRP, LVEF, excess volumes of $\mathrm{CM}$ and preoperative statins therapy.

Male (OR: 0.672, 95\%CI: $0.558 \sim 0.809 ; P<0.001$ ), younger (OR: $1.026,95 \% \mathrm{CI}: 1.016 \sim 1.035 ; P<0.001$ ), higher LVEF $(\mathrm{OR}=0.977,95 \% \mathrm{CI}: 0.971 \sim 0.984 ; P<$ 0.001 ) and preoperative statins (OR: $0.575,95 \% \mathrm{CI}$ : $0.466 \sim 0.709 ; P<0.001)$ were associated with lower odds (i.e. protective) of PC-AKI, while CRP (OR: 1.009, 95\%CI: $1.006 \sim 1.012 ; P<0.001$ ), diabetes (OR: 1.226, 95\%CI: $1.012 \sim 1.484 ; P=0.037)$ and excess volumes of $\mathrm{CM}$ (OR: 1.733, 95\%CI: $1.156 \sim 2.596$; $P=0.008$ ) indicated higher odds (i.e. increased risk) of PC-AKI.

Furthermore, in multivariate linear regression analysis, preoperative statins therapy was associated with lower percentage of elevated creatinine levels $(\beta:-0.118 ; P<$ 0.001), as shown in Table 3.
In addition, as shown in Table 4, the type of statins (rosuvastatin or atorvastatin) had no significant correlation with PC-AKI.

\section{Path analysis}

Structural equation modeling with observed variables in SPSS Amos was applied to test the relationships between preoperative statins therapy and PC-AKI (Figs. 1, 2, and 3), while controlling for sociodemographic variables. The results showed that preoperative statins therapy was significantly negatively associated with PC-AKI $(\beta=-.0 .085, P<0.001)$ and LDL-C had no significant effect on PC-AKI $(P=$ $0.311)$. This indicated that LDL-C was not a mediator for the relationship between preoperative statins therapy and PC-AKI $(P=0.277)$ (Fig. 1$)$. In addition, CRP positively predicted PC-AKI $(\beta=0.162, P<0.001)$ but CRP in patients with and without preoperative statins therapy was not significantly different $(P=0.601)$. This also indicated that CRP was not a mediator for the relationship between preoperative statins therapy and PC-AKI $(P=0.596)$ (Fig. 2). However, CRP positively

Table 2 Univariate and multivariate logistic association for PC-AKI among the whole population

\begin{tabular}{|c|c|c|c|c|c|c|c|c|}
\hline & \multicolumn{4}{|c|}{ Univariable Analysis } & \multicolumn{4}{|c|}{ Multivariable Analysis } \\
\hline & B & OR & $95 \% \mathrm{Cl}$ & $P$ & B & OR & $95 \% \mathrm{Cl}$ & $P$ \\
\hline Male & -0.312 & 0.732 & $0.625-0.858$ & $<0.001$ & -0.397 & 0.672 & $0.558-0.809$ & $<0.001$ \\
\hline Age & 0.025 & 1.025 & $1.018-1.033$ & $<0.001$ & 0.025 & 1.026 & $1.016-1.035$ & $<0.001$ \\
\hline Smoking & -0.201 & 0.818 & $0.66-1.014$ & 0.067 & 0.003 & 1.003 & $0.771-1.304$ & 0.984 \\
\hline Drinking & -0.292 & 0.746 & $0.593-0.939$ & 0.013 & -0.037 & 0.964 & $0.736-1.262$ & 0.787 \\
\hline Hypertension & 0.093 & 1.097 & $0.933-1.29$ & 0.261 & & & & \\
\hline Diabetes & 0.261 & 1.299 & $1.092-1.545$ & 0.003 & 0.203 & 1.226 & $1.012-1.484$ & 0.037 \\
\hline eGFR & -0.007 & 0.993 & $0.99-0.996$ & $<0.001$ & 0.003 & 1.003 & $0.998-1.007$ & 0.209 \\
\hline Uric acid & 0 & 1 & $0.999-1.001$ & 0.928 & & & & \\
\hline LDL-C & -0.025 & 0.976 & $0.895-1.063$ & 0.573 & & & & \\
\hline CRP & 0.011 & 1.011 & $1.008-1.014$ & $<0.001$ & 0.009 & 1.009 & $1.006-1.012$ & $<0.001$ \\
\hline LVEF & -0.021 & 0.979 & $0.973-0.985$ & $<0.001$ & -0.023 & 0.977 & $0.971-0.984$ & $<0.001$ \\
\hline Excess volumes of CM & 0.479 & 1.614 & $1.15-2.266$ & 0.006 & 0.55 & 1.733 & $1.156-2.596$ & 0.008 \\
\hline Iso-osmolar CM & -0.001 & 0.999 & $0.846-1.179$ & 0.988 & & & & \\
\hline Contrast Volume & 0 & 1 & $0.999-1.001$ & 0.557 & & & & \\
\hline Pre-operative statin therapy & -0.53 & 0.589 & $0.488-0.711$ & $<0.001$ & -0.554 & 0.575 & $0.466-0.709$ & $<0.001$ \\
\hline Prior myocardial infarction & 0.163 & 1.177 & $0.925-1.497$ & 0.185 & & & & \\
\hline Prior PCl & 0.134 & 1.144 & $0.956-1.369$ & 0.143 & & & & \\
\hline Prior CABG & -0.092 & 0.912 & $0.579-1.437$ & 0.691 & & & & \\
\hline Prior cardiac surgery (except CABG) & -0.01 & 0.991 & $0.644-1.524$ & 0.965 & & & & \\
\hline Angiography combined with $\mathrm{PCl}$ & 0.054 & 1.055 & $0.904-1.232$ & 0.496 & & & & \\
\hline Multi vessel PCl & -0.003 & 0.997 & $0.789-1.258$ & 0.977 & & & & \\
\hline Total length of stents & -0.006 & 0.994 & $0.988-1$ & 0.071 & & & & \\
\hline
\end{tabular}

Abbreviations: $P C$-AKI post-contrast acute kidney injury, eGFR estimated glomerular filtration rate, $L D L-C$ low-density lipoprotein cholesterol, $C R P C$-reactive protein, $\angle V E F$ left ventricular ejection fractions, $C M$ contrast medium, $A C E I$ angiotensin converting enzyme inhibitors, $P C I$ percutaneous coronary intervention, $C A B G$ coronary artery bypass grafting 
Table 3 Univariate and multivariate linear association for Percentage of elevated creatinine among the whole population

\begin{tabular}{|c|c|c|c|c|c|c|}
\hline & \multicolumn{3}{|c|}{ Univariable Analysis } & \multicolumn{3}{|c|}{ Multivariable Analysis } \\
\hline & $\bar{B}$ & $\beta$ & $P$ & $\bar{B}$ & $\beta$ & $P$ \\
\hline Male & -1.973 & -0.024 & 0.109 & & & \\
\hline Age & 0.234 & 0.065 & $<0.001$ & 0.238 & 0.068 & $<0.001$ \\
\hline Smoking & -2.232 & -0.022 & 0.151 & & & \\
\hline Drinking & -3.535 & -0.033 & 0.029 & -1.56 & -0.015 & 0.353 \\
\hline Hypertension & -0.909 & -0.011 & 0.454 & & & \\
\hline Diabetes & 3.007 & 0.033 & 0.028 & 2.824 & 0.032 & 0.045 \\
\hline eGFR & -0.027 & -0.016 & 0.286 & & & \\
\hline Uric acid & 0.003 & 0.009 & 0.562 & & & \\
\hline LDL-C & -0.335 & -0.008 & 0.603 & & & \\
\hline CRP & 0.224 & 0.13 & $<0.001$ & 0.176 & 0.106 & $<0.001$ \\
\hline LVEF & -0.345 & -0.117 & $<0.001$ & -0.294 & -0.102 & $<0.001$ \\
\hline Excess volumes of $\mathrm{CM}$ & 6.616 & 0.036 & 0.022 & 4.567 & 0.025 & 0.11 \\
\hline Iso-osmolar CM & -0.027 & 0 & 0.983 & & & \\
\hline Contrast Volume & -0.002 & -0.003 & 0.834 & & & \\
\hline Pre-operative statin therapy & -11.39 & -0.11 & $<0.001$ & -12.06 & -0.118 & $<0.001$ \\
\hline Prior myocardial infarction & -0.733 & -0.002 & 0.874 & & & \\
\hline Prior PCl & -1.948 & -0.011 & 0.457 & & & \\
\hline Prior CABG & -8.818 & -0.013 & 0.378 & & & \\
\hline Prior cardiac surgery (except CABG) & 2.18 & 0.003 & 0.827 & & & \\
\hline Angiography combined with $\mathrm{PCl}$ & -0.978 & -0.013 & 0.406 & & & \\
\hline Multi vessel PCI & -1.287 & -0.019 & 0.416 & & & \\
\hline Total length of stents & 0.001 & 0.001 & 0.972 & & & \\
\hline
\end{tabular}

Abbreviations: $P C$-AKI post-contrast acute kidney injury, eGFR estimated glomerular filtration rate, $L D L-C$ low-density lipoprotein cholesterol, $C R P C$-reactive protein, LVEF left ventricular ejection fractions, $C M$ contrast medium, $A C E l$ angiotensin converting enzyme inhibitors, $P C I$ percutaneous coronary intervention, $C A B G$ coronary artery bypass grafting

predicted PC-AKI $(\beta=0.039, P=0.009)$, and therefore, "LDL-C $\rightarrow$ CRP" was a partial mediator for the relationship between preoperative statins therapy and PCAKI. The value of this effect was less than 0 and tended to 0, with a bootstrap (50,000 samples) $95 \%$ confidence intervals of -0.001 to $0(P=0.007)$. Since this confidence interval did not include zero, it was concluded that there was a significant mediation effect of "LDL-C $\rightarrow$ CRP" on the relationship between preoperative statins therapy and PC-AKI. Still, it only explained $<1 \%$ effects (Fig. 3).

\section{Discussion}

Statins are widely used as a preventive therapy for coronary artery disease, suggesting their potential usefulness in PC-AKI. The current study provided evidence that long-term use of statins independently decreased the risk of PC-AKI. This favorable effect seems to be a class effect of statins regardless of its type, and was not achieved through the statins' lipid-lowering and antiinflammatory mechanisms but other unknown mechanisms that need to be explored. These findings have important implications for patients undergoing CAG or PCI.

With the enhanced role of $\mathrm{CM}$ in the cardiovascular field, the focus on PC-AKI is expected to rise. Prevention of PC-AKI could be reflected as lower mortality, morbidity, treatment costs, and length of hospital [28, 29]. Hence, looking for preventive therapies is needed. In this regard, the role of statins in the preventing PCAKI remains controversial due to contradicting reports [6-15]. Notably, however, recent meta-analysis [30], including 8 RCTs and 4635 patients, showed that statins pretreatment was effectively prevented PC-AKI, which is consistent with this study. The inconsistency observed among studies may be because statins lack renal protection in patients with advanced kidney disease. Differences in the proportions of patients with severe kidney disease could result in differences in conclusions. In this study, the proportion of patients with poor renal function was small. Also, few studies addressed the relevance of long-term use of statins before receiving $\mathrm{CM}$ and $\mathrm{PC}$ AKI. Differences in the duration of receiving statins could also explain some of these inconsistencies. This 
Table 4 Univariate and multivariate logistic association for PC-AKI among patients with pre-operative statin therapy

\begin{tabular}{|c|c|c|c|c|c|c|c|c|}
\hline & \multicolumn{4}{|c|}{ Univariable Analysis } & \multicolumn{4}{|c|}{ Multivariable Analysis } \\
\hline & $\bar{B}$ & OR & $95 \% \mathrm{Cl}$ & $P$ & $\bar{B}$ & OR & $95 \% \mathrm{Cl}$ & $P$ \\
\hline Male & -0.3 & 0.741 & $0.618-0.888$ & 0.001 & -0.403 & 0.668 & $0.541-0.826$ & $<0.001$ \\
\hline Age & 0.027 & 1.028 & $1.019-1.037$ & $<0.001$ & 0.025 & 1.025 & $1.014-1.036$ & $<0.001$ \\
\hline Smoking & -0.224 & 0.799 & $0.629-1.016$ & 0.067 & -0.035 & 0.965 & $0.72-1.293$ & 0.812 \\
\hline Drinking & -0.316 & 0.729 & $0.563-0.944$ & 0.017 & -0.009 & 0.991 & $0.734-1.339$ & 0.954 \\
\hline Hypertension & 0.207 & 1.229 & $1.016-1.487$ & 0.033 & 0.064 & 1.066 & $0.861-1.318$ & 0.559 \\
\hline Diabetes & 0.413 & 1.511 & $1.251-1.825$ & $<0.001$ & 0.283 & 1.326 & $1.078-1.632$ & 0.008 \\
\hline eGFR & -0.008 & 0.992 & $0.989-0.996$ & $<0.001$ & 0.004 & 1.004 & 0.999-1.009 & 0.097 \\
\hline Uric acid & 0 & 1 & $0.999-1.001$ & 0.901 & & & & \\
\hline LDL-C & 0.003 & 1.003 & $0.913-1.102$ & 0.945 & & & & \\
\hline CRP & 0.012 & 1.013 & $1.009-1.016$ & $<0.001$ & 0.01 & 1.011 & $1.007-1.014$ & $<0.001$ \\
\hline LVEF & -0.025 & 0.975 & $0.969-0.981$ & $<0.001$ & -0.026 & 0.974 & $0.967-0.981$ & $<0.001$ \\
\hline Excess volumes of CM & 0.571 & 1.77 & $1.241-2.526$ & 0.002 & 0.615 & 1.85 & $1.205-2.84$ & 0.005 \\
\hline Iso-osmolar CM & 0.001 & 1.001 & $0.831-1.204$ & 0.996 & & & & \\
\hline Contrast Volume & 0.001 & 1.001 & $1-1.002$ & 0.119 & & & & \\
\hline Types of statins, Atorvastatin & 0.083 & 1.087 & $0.929-1.271$ & 0.297 & 0.051 & 1.052 & $0.887-1.249$ & 0.558 \\
\hline Prior myocardial infarction history & 0.164 & 1.178 & $0.64-2.168$ & 0.598 & & & & \\
\hline Prior $\mathrm{PCl}$ history & 0.075 & 1.077 & $0.754-1.54$ & 0.682 & & & & \\
\hline CABG history & -0.946 & 0.388 & $0.051-2.973$ & 0.362 & & & & \\
\hline Cardiac surgery history (except CABG) & 0.814 & 2.257 & $0.693-7.353$ & 0.177 & & & & \\
\hline Angiography combined with $\mathrm{PCl}$ & 0.202 & 1.224 & $1.027-1.459$ & 0.024 & & & & \\
\hline Multi vessel $\mathrm{PCl}$ & 0.035 & 1.035 & $0.813-1.318$ & 0.779 & & & & \\
\hline Total length of stents & -0.005 & 0.995 & $0.989-1.001$ & 0.127 & & & & \\
\hline
\end{tabular}

Abbreviations: PC-AKI post-contrast acute kidney injury, eGFR estimated glomerular filtration rate, $L D L-C$ low-density lipoprotein cholesterol, CRP C-reactive protein, LVEF left ventricular ejection fractions, $C M$ contrast medium, $A C E l$ angiotensin converting enzyme inhibitors, $P C I$ percutaneous coronary intervention, $C A B G$ coronary artery bypass grafting

study proved that those patients who received long-term use of statins would have a lower risk of PC-AKI.

The pleiotropic effect of statins may have important clinical significance in preventing PC-AKI. McCullough's review claimed that statins exert renoprotective effects in PC-AKI via blocking the absorption of
CM into renal tubular cells, reducing oxidative stress, anti-proliferation of mesangial cells and antiinflammation [31]. In 2019, Mehran's review suggested that that statins reduce the risk of PC-AKI via their anti-inflammatory and antioxidant properties [20]. Lipid-lowering agents like rosuvastatin,

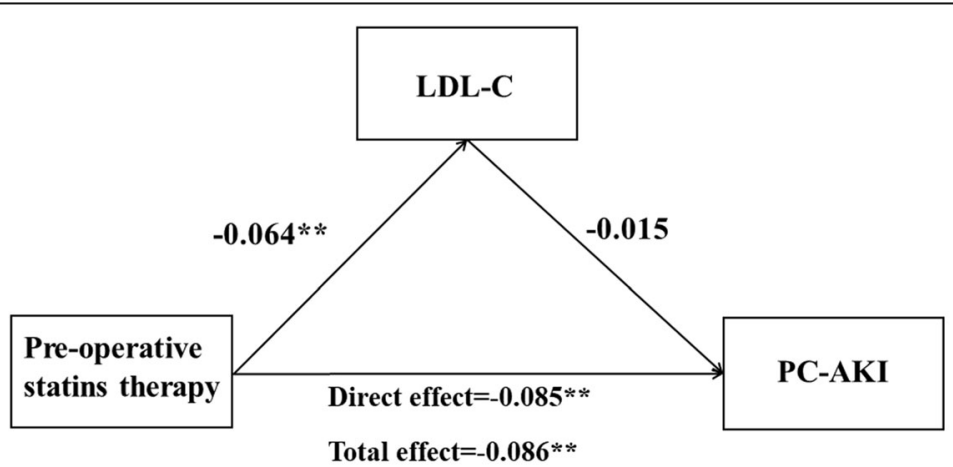

Note: $* * P<0.001$.Values on paths are path coefficients (standardized $\beta$ s)

Fig. 1 Model of the mediating effect of LDL-C on the association between Pre-operative statins therapy and PC-AKI 


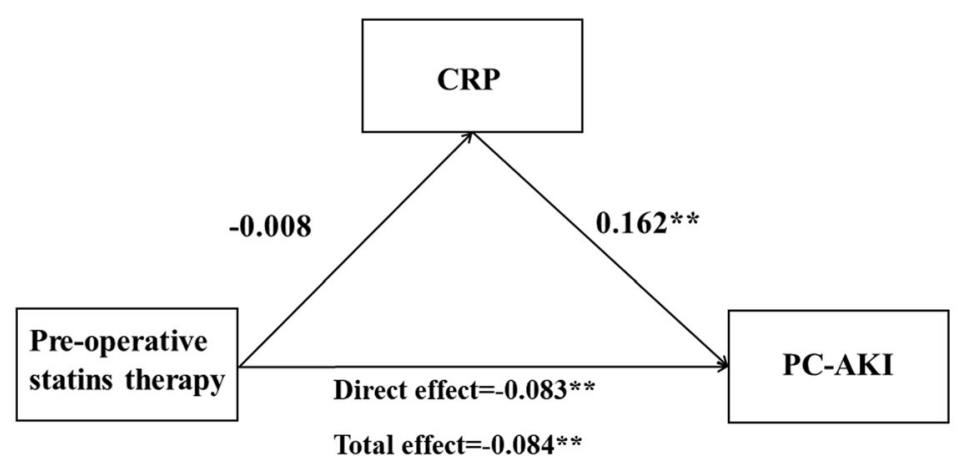

Note: $* * P<0.001$.Values on paths are path coefficients (standardized $\beta$ s)

Fig. 2 Model of the mediating effect of CRP on the association between Pre-operative statin therapy and CIAKI

atorvastatin, and simvastatin are currently used as potential pharmacological interventions in PC-AKI animal models [18, 32, 33]. Taken all together, these reports indicate that statins could decrease PC-AKI through a variety of physiological pathways, such as modulation to nitric oxide, oxidative stress, inflammatory responses, and apoptotic processes. However, there has been few clinical research to explore the intermediate mechanism of statins.

In the current study, it was found that the lower CRP reduced PC-AKI occurrence, while statins were not associated with the CRP. Meanwhile, there was no significant correlation between LDL-C and the occurrence of PC-AKI. Thus, the protective role of statins in PC-AKI has not been achieved through lipid-lowering and antiinflammatory effects, but other unknown mechanisms. These mechanisms could be anti-proliferative [22, 34], antioxidant [23-26], immunomodulatory [35, 36], neuroprotective [37, 38], anti-diabetes [39], which need to be explored.

\section{Study strengths and limitations}

The current study has several strengths. This includes being a multicenter study with considerable sample size. Also, it addressed a novel and clinically relevant topic by exploring the relationship between long-term use of statins before receiving $\mathrm{CM}$ and the odds of $\mathrm{PC}-\mathrm{AKI}$, and the intermediate mechanisms explaining the effects of statins. Findings from this analysis might support longterm use of statins before CAG or PCI, which may contribute to lower risk of PC-AKI and subsequently lower mortality, morbidity, treatment costs and length of hospital stay.

This study has potential limitations, as well. First, it was a retrospective observational study. A doubleblinded randomized-controlled trial is needed to warrant long-term statins used to prevent PC-AKI in patients undergoing CM. Second, the majority of patients received statins. Likely, statins were more frequently prescribed in patients with elevated LDL-C levels, which could generate bias. Third, vascular access has been

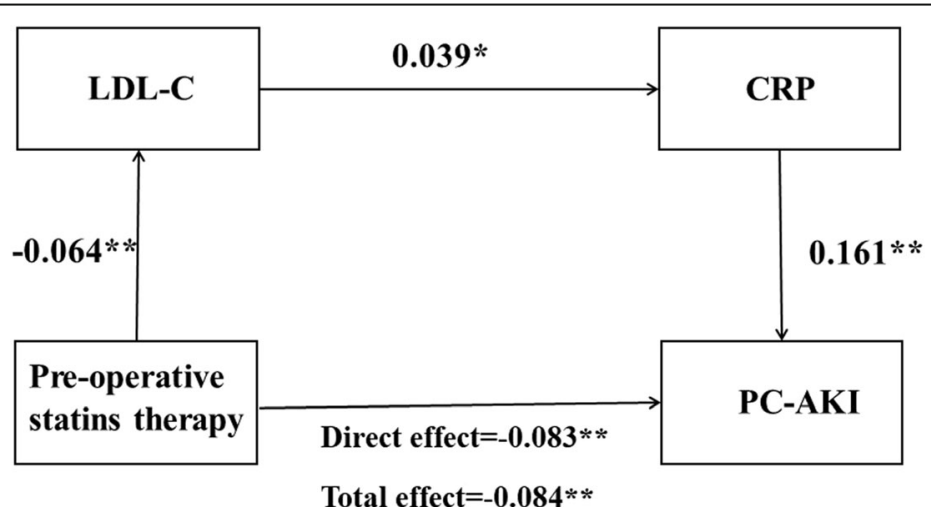

Note: $* P<0.01$. Values on paths are path coefficients, $* * P<0.001$.

Values on paths are path coefficients (standardized $\beta$ s)

Fig. 3 Model of the mediating effect of LDL-C, CRP on the association between Pre-operative statins therapy and PC-AKI 
demonstrated to affect the risk of AKI after PCI, with the radial access proven to be protective compared with the femoral access [40]. However, relevant information was not available and hence residual confounding due to this factor and others remains a possibility. Furthermore, many clinical test indicators cannot temporarily be obtained, such as anti-oxidative stress and antiproliferation, to further explore the intermediate mechanism of statins.

\section{Conclusion}

Preoperative statins therapy is an independent protective factor of PC-AKI, which is not affected by the type of statins and not achieved by the lipid-lowering effect or anti-inflammatory effects. Patients not on preoperative statins therapy before CAG/PCI tend to have a higher incidence of PC-AKI, which informs clinical workers to be more cautious in using the dose of contrast media, and to take preventive measures more actively in clinical practice, such as fluid rehydration. These findings suggest the potential usefulness of preoperative statins therapy in preventing PC-AKI before CAG/PCI.

\section{Abbreviations \\ ESUR: European Society of Urogenital Radiology; ACEl: Angiotensin converting enzyme-inhibitors; BMI: Body mass index; CKD: Chronic kidney disease; CRP: C-reactive protein; CABG: Coronary artery bypass grafting; PCl: Percutaneous coronary intervention; HIS: Hospital Information System; PC-AKI: Post-Contrast acute kidney injury; LDL-C: Low-density lipoprotein cholesterol; CAG: Coronary angiography; CM: Contrast medium; eGFR: estimated glomerular filtration rate; SPSS: Statistical Package for Social Sciences; LVEF: Left Ventricular Ejection Fractions}

\section{Acknowledgements}

With many thanks to HEMA DARINEE TEEROOVENGADUM, for her linguistic assistance during the preparation of this manuscript. And EditSprings provided the expert linguistic services.

\section{Authors' contributions}

The study was designed by Min Wang, Wenbin Zhang and Yi Luan; Maoning Lin, Tian Xu and Duanbin Li performed the statistical analysis; Maoning Lin and Tian Xu drafted the manuscript. All authors gave comments and suggestions, and approved publication.

\section{Funding}

This study is supported by the National Natural Science Foundation of China (81800212 and 82070408).

\section{Availability of data and materials}

Definitely, the corresponding author would like to provide data for proper requests.

\section{Declarations}

\section{Ethics approval and consent to participate}

The study passed ethical review by the Ethics Committee of Sir Run Run Shaw Hospital, College of Medicine, Zhejiang University. No informed consent was available due to the retrospective design.

\section{Consent for publication}

All authors confirmed and approved to publication.

\section{Competing interests}

All authors have no competing interests.

\section{Author details}

'Department of Cardiovascular Diseases, Sir Run Run Shaw Hospital, College of Medicine, Zhejiang University, No 3 East of Qinchun Road, Hangzhou, Zhejiang 310000, People's Republic of China. ${ }^{2}$ Key Laboratory of Cardiovascular Intervention and Regenerative Medicine of Zhejiang Province, Hangzhou 310000, People's Republic of China. ${ }^{3}$ Department of Information Technology, Sir Run Run Shaw Hospital, College of Medicine, Zhejiang University, No 3 East of Qingchun Road, Hangzhou, Zhejiang 310000, People's Republic of China.

Received: 3 April 2021 Accepted: 13 June 2021

Published online: 05 July 2021

\section{References}

1. van der Molen AJ, Reimer P, Dekkers IA, Bongartz G, Bellin MF, Bertolotto M, et al. Post-contrast acute kidney injury - part 1: definition, clinical features, incidence, role of contrast medium and risk factors : recommendations for updated ESUR contrast medium safety committee guidelines. Eur Radiol. 2018;28(7):2845-55. https://doi.org/10.1007/s00330-017-5246-5.

2. van der Molen AJ, Reimer P, Dekkers IA, Bongartz G, Bellin MF, Bertolotto M, et al. Post-contrast acute kidney injury. Part 2: risk stratification, role of hydration and other prophylactic measures, patients taking metformin and chronic dialysis patients: recommendations for updated ESUR contrast medium safety committee guidelines. Eur Radiol. 2018;28(7):2856-69. https://doi.org/10.1007/s00330-017-5247-4.

3. Fahling $M$, Seeliger $E$, Patzak $A$, Persson PB. Understanding and preventing contrast-induced acute kidney injury. Nat Rev Nephrol. 2017;13(3):169-80. https://doi.org/10.1038/nrneph.2016.196.

4. Virani SS, Alonso A, Benjamin EJ, Bittencourt MS, Callaway CW, Carson AP, et al. Heart disease and stroke Statistics-2020 update: a report from the American Heart Association. Circulation. 2020;141(9):e139-596. https://doi. org/10.1161/CIR.0000000000000757.

5. Neumann FJ, Sousa-Uva M, Ahlsson A, Alfonso F, Banning AP, Benedetto U, et al. ESC/EACTS Guidelines on myocardial revascularization. Eur Heart J. 2018;2019(40):87-165.

6. Zhou X, Dai J, Xu X, Wang Z, Xu H, Chen J, et al. Comparative efficacy of statins for prevention of contrast-induced acute kidney injury in patients with chronic kidney disease: a network meta-analysis. Angiology. 2019;70(4): 305-16. https://doi.org/10.1177/0003319718801246.

7. Giacoppo D, Gargiulo G, Buccheri S, Aruta P, Byrne RA, Cassese S, et al. Preventive strategies for contrast-induced acute kidney injury in patients undergoing percutaneous coronary procedures: evidence from a hierarchical Bayesian network meta-analysis of 124 trials and 28240 patients. Circ Cardiovasc Interv. 2017;10(5). https://doi.org/10.1161/ CIRCINTERVENTIONS.116.004383.

8. Li H, Wang C, Liu C, Li R, Zou M, Cheng G. Efficacy of short-term statin treatment for the prevention of contrast-induced acute kidney injury in patients undergoing coronary angiography/percutaneous coronary intervention: a meta-analysis of 21 randomized controlled trials. Am J Cardiovasc Drugs. 2016;16(3):201-19. https://doi.org/10.1007/s40256-016-01 64-5.

9. Wang N, Qian P, Yan TD, Phan K. Periprocedural effects of statins on the incidence of contrast-induced acute kidney injury: a systematic review and trial sequential analysis. Int J Cardiol. 2016;206:143-52. https://doi.org/10.101 6/j.jijcard.2016.01.004.

10. Thompson K, Razi R, Lee MS, Shen A, Stone GW, Hiremath S, et al. Statin use prior to angiography for the prevention of contrast-induced acute kidney injury: a meta-analysis of 19 randomised trials. Eurolntervention. 2016;12(3): 366-74. https://doi.org/10.4244/EIJY15M05_03.

11. Park JH, Shin HJ, Choi JY, Lim JS, Park MS, Kim MJ, et al. Is there association between statin usage and contrast-associated acute kidney injury after intravenous administration of iodine-based contrast media in enhanced computed tomography? Eur Radiol. 2020;30(10):5261-71. https://doi.org/1 0.1007/s00330-020-06897-4.

12. Sreenivasan J, Khan MS, Li H, Zhuo M, Patel A, Fugar S, et al. Statins and incidence of contrast-induced acute kidney injury following coronary angiography - five year experience at a tertiary care center. Cardiovasc Revasc Med. 2019;20(8):654-8. https://doi.org/10.1016/j.carrev.2018.09.012.

13. Cai L, Bai X, Lei H, Wu H, Liu Y, Zhu Q, et al. High plasma exposure of statins associated with increased risk of contrast-induced acute kidney injury in 
Chinese patients with coronary artery disease. Front Pharmacol. 2018;9:427. https://doi.org/10.3389/fphar.2018.00427.

14. Toso A, Maioli M, Leoncini M, Gallopin M, Tedeschi D, Micheletti C, et al. Usefulness of atorvastatin $(80 \mathrm{mg}$ ) in prevention of contrast-induced nephropathy in patients with chronic renal disease. Am J Cardiol. 2010; 105(3):288-92. https://doi.org/10.1016/j.amjcard.2009.09.026.

15. Kandula P, Shah R, Singh N, Markwell SJ, Bhensdadia N, Navaneethan SD. Statins for prevention of contrast-induced nephropathy in patients undergoing non-emergent percutaneous coronary intervention. Nephrology (Carlton). 2010;15(2):165-70. https:/doi.org/10.1111/j.1440-1797.2009.01204.x.

16. Kusirisin P, Chattipakorn SC, Chattipakorn N. Contrast-induced nephropathy and oxidative stress: mechanistic insights for better interventional approaches. J Transl Med. 2020;18(1):400. https://doi.org/10.1186/s12967-02 0-02574-8.

17. Vlachopanos G, Schizas D, Hasemaki N, Georgalis A. Pathophysiology of contrast-induced acute kidney injury (CIAKI). Curr Pharm Des. 2019;25(44): 4642-7. https://doi.org/10.2174/1381612825666191210152944.

18. Wang XL, Zhang T, Hu LH, Sun SQ, Zhang WF, Sun Z, et al. Comparison of effects of different statins on contrast-induced acute kidney injury in rats: histopathological and biochemical findings. Oxidative Med Cell Longev. 2017;2017:6282486.

19. Zhou MS, Schuman IH, Jaimes EA, Raij L. Renoprotection by statins is linked to a decrease in renal oxidative stress, TGF-beta, and fibronectin with concomitant increase in nitric oxide bioavailability. Am J Physiol Renal Physiol. 2008;295(1):F53-9. https://doi.org/10.1152/ajprenal.00041.2008.

20. Mehran R, Dangas GD, Weisbord SD. Contrast-associated acute kidney injury. N Engl J Med. 2019;380(22):2146-55. https://doi.org/10.1056/NEJMra1 805256.

21. Heyman SN, Rosen $S$, Khamaisi M, Idée JM, Rosenberger C. Reactive oxygen species and the pathogenesis of radiocontrast-induced nephropathy. Investig Radiol. 2010;45(4):188-95. https://doi.org/10.1097/RLI.0b013e3181d2 eed8.

22. Bedi O, Dhawan V, Sharma PL, Kumar P. Pleiotropic effects of statins: new therapeutic targets in drug design. Naunyn Schmiedebergs Arch Pharmacol. 2016;389(7):695-712. https://doi.org/10.1007/s00210-016-1252-4.

23. Kojanian H, Szafran-Swietlik A, Onstead-Haas LM, Haas MJ, Mooradian AD. Statins prevent dextrose-induced endoplasmic reticulum stress and oxidative stress in endothelial and HepG2 cells. Am J Ther. 2016;23(6): e1456-63. https://doi.org/10.1097/MJT.0000000000000073.

24. Ersoy A, Koc ER, Sahin S, Duzgun U, Acar B, Ithan A. Possible effects of rosuvastatin on noise-induced oxidative stress in rat brain. Noise Health. 2014;16(68):18-25. https://doi.org/10.4103/1463-1741.127849.

25. Alanazi F. Pravastatin provides antioxidant activity and protection of erythrocytes loaded Primaquine. Int J Med Sci. 2010;7(6):358-65. https://doi. org/10.7150/ijms.7.358.

26. Wassmann S, Laufs U, Bäumer AT, Müller K, Konkol C, Sauer H, et al. Inhibition of geranylgeranylation reduces angiotensin II-mediated free radical production in vascular smooth muscle cells: involvement of angiotensin AT1 receptor expression and Rac1 GTPase. Mol Pharmacol. 2001;59(3):646-54. https://doi.org/10.1124/mol.59.3.646.

27. Nagashima T, Okazaki H, Yudoh K, Matsuno H, Minota S. Apoptosis of rheumatoid synovial cells by statins through the blocking of protein geranylgeranylation: a potential therapeutic approach to rheumatoid arthritis. Arthritis Rheum. 2006;54(2):579-86. https://doi.org/10.1002/art.21 564.

28. Hossain MA, Costanzo E, Cosentino J, Patel C, Qaisar H, Singh V, et al. Contrast-induced nephropathy: pathophysiology, risk factors, and prevention. Saudi J Kidney Dis Transpl. 2018;29(1):1-9. https://doi.org/10.41 03/1319-2442.225199.

29. Prasad A, Ortiz-Lopez C, Khan A, Levin D, Kaye DM. Acute kidney injury following peripheral angiography and endovascular therapy: a systematic review of the literature. Catheter Cardiovasc Interv. 2016;88(2):264-73. https://doi.org/10.1002/ccd.26466.

30. Cho A, Lee YK, Sohn SY. Beneficial effect of statin on preventing contrastinduced acute kidney injury in patients with renal insufficiency: a metaanalysis. Medicine (Baltimore). 2020;99(10):e19473. https://doi.org/10.1097/ MD.0000000000019473.

31. McCullough PA, Choi JP, Feghali GA, Schussler JM, Stoler RM, Vallabahn RC, et al. Contrast-induced acute kidney injury. J Am Coll Cardiol. 2016;68(13): 1465-73. https://doi.org/10.1016/j.jacc.2016.05.099.
32. Deng J, Wu G, Yang C, Li Y, Jing Q, Han Y. Rosuvastatin attenuates contrastinduced nephropathy through modulation of nitric oxide, inflammatory responses, oxidative stress and apoptosis in diabetic male rats. J Transl Med. 2015:13(1):53. https://doi.org/10.1186/s12967-015-0416-1.

33. Al-Otaibi KE, Al Elaiwi AM, Tariq M, Al-Asmari AK. Simvastatin attenuates contrast-induced nephropathy through modulation of oxidative stress, proinflammatory myeloperoxidase, and nitric oxide. Oxidative Med Cell Longev. 2012;2012:831748.

34. Xu B, Wang Q, Sung C. Telomerase inhibitory effects of red pigment Rubropunctatin and statin monacolin $\mathrm{L}$ isolated from red yeast Rice. Genes (Basel). 2017:8(5). https://doi.org/10.3390/genes8050129.

35. Palinski W, Tsimikas S. Immunomodulatory effects of statins: mechanisms and potential impact on arteriosclerosis. J Am Soc Nephrol. 2002;13(6): 1673-81. https://doi.org/10.1097/01.ASN.0000018400.39687.8C.

36. Smaldone C, Brugaletta S, Pazzano V, Liuzzo G. Immunomodulator activity of 3-hydroxy-3-methilglutaryl-CoA inhibitors. Cardiovasc Hematol Agents Med Chem. 2009;7(4):279-94. https://doi.org/10.2174/187152509789541864.

37. Kumar A, Sharma N, Gupta A, Kalonia H, Mishra J. Neuroprotective potential of atorvastatin and simvastatin (HMG-CoA reductase inhibitors) against 6hydroxydopamine (6-OHDA) induced Parkinson-like symptoms. Brain Res. 2012;1471:13-22. https://doi.org/10.1016/j.brainres.2012.06.050.

38. Yavuz C, Demirtas S, Guclu O, Karahan O, Caliskan A, Yazici S, et al. Rosuvastatin may have neuroprotective effect on spinal cord ischemia reperfusion injury. CNS Neurol Disord Drug Targets. 2013;12(7):1011-6. https://doi.org/10.2174/18715273113129990085.

39. Li F, Drel VR, Szabó C, Stevens MJ, Obrosova IG. Low-dose poly (ADP-ribose) polymerase inhibitor-containing combination therapies reverse early peripheral diabetic neuropathy. Diabetes. 2005;54(5):1514-22. https://doi. org/10.2337/diabetes.54.5.1514.

40. Andò G, Gragnano F, Calabrò P, Valgimigli M. Radial vs femoral access for the prevention of acute kidney injury (AKI) after coronary angiography or intervention: a systematic review and meta-analysis. Cathete Cardiovasc Interv. 2018;92(7):E518-26. https://doi.org/10.1002/ccd.27903.

\section{Publisher's Note}

Springer Nature remains neutral with regard to jurisdictional claims in published maps and institutional affiliations.

Ready to submit your research? Choose BMC and benefit from:

- fast, convenient online submission

- thorough peer review by experienced researchers in your field

- rapid publication on acceptance

- support for research data, including large and complex data types

- gold Open Access which fosters wider collaboration and increased citations

- maximum visibility for your research: over $100 \mathrm{M}$ website views per year

At $\mathrm{BMC}$, research is always in progress.

Learn more biomedcentral.com/submissions 